\title{
Connecting Faith through Theatre: Barazanyee as a Semi-Ritual Performance in Thai Muslim Communities
}

\author{
Khalid Midam \\ Lecturer, Faculty of Music and Performing Arts, Burapha University, \\ Chonburi, Thailand \\ khalid@go.buu.ac.th
}

\begin{abstract}
This research paper examines the creative process used to connect young Muslims with their experience, their faith, and their community through a community-based performance. It also stresses the different levels of connections that resulted from the performance itself. The author sought to reconnect Barazan'yee, an important Arabic poetic chant, to people in the Bangkok Islamic community using tools from community theatre. The performance design process allowed them to tell their own story in relation to Bar'zanyee poetry in ways that are meaningful to them and their community, thus connecting their lives to the life of Prophet Muhammad. The first performance was in a public theatre resulted in a shift in structure and participation choices for audience in the second performance at a public theatre. Although both performances were conducted in a semi-ritualized environment of the Muslim community, the latter better engaged both the performers and audience.
\end{abstract}

\section{Keywords}

community-based theatre - Muslim theatre - semi-ritual performance - Barazan'yee 
Thai Muslim communities have borrowed several forms of art and culture from Malay or Arabic culture. This influence has produced some common practices which function both as rituals and as community performances, but in which participants may not always understand what they are reciting or hearing. One good example of this in Bangkok Islamic communities is the practice of Barazan'yee, a special form of Arabic poetry. This research project seeks to work with this form of poetry as a starting point, trying to reconnect it with Muslim communities in Bangkok using tools from modern theatre. The researcher sought to introduce several tools from community-based theatre and story theatre into Islamic communities in Bangkok to develop both a working process and a performance based on Barazan'yee singing with research participants. ${ }^{2}$

Before becoming a lecturer in the Faculty of Music and Performing Arts at Burapha University, I had worked in contemporary theatre for a decade. As an actor, I performed in many theatre performances, but I have had many other roles in theatre-making, too. I directed youth theatre performances for children in my Muslim community. I sought to promote theatre in my community so that people could accept theatre as an expressive form that could benefit the community. I wanted to show them how theatre could be a tool to help community development and a good medium to convey and promote religious understanding among Muslims.

After a decade of working in theatre, I felt I needed to find a new way of integrating theatre with Islamic culture. I decided to start with some problem that my community is facing, focusing on the role of Barazan'yee poetry in communal ceremonies.

To help address this problem, I turned to the tools of community theatre. In simplest terms, community theatre is a theatre made by and intended for, members of a specific community. It is a special kind of performance in which socio-cultural issues of a community are developed into performances by members of the community themselves, that is, by the same people who are involved in the socio-cultural life of the community. They develop and perform their work by and for members of the community. Van Erven $(2001,2-3)$ argues that community theatre puts

1 See the photos of this article at the URL, figshare.com

2 The author would like to thank the two anonymous readers for their insightful comments and suggestions for improvement on an earlier draft of this paper. In addressing these issues in this version of the paper, its focus and details have improved. 
"emphasis on local and/or personal stories (rather than pre-written scripts) that are first processed through improvisation and then collectively shaped into theatre under the guidance either of outside professional artists... or of local amateur artists residing among groups of people that... could perhaps best be called 'peripheral'. Community theatre yields grass roots performances in which the participating community residents themselves perform and during the creative process of which they have substantial input." It "privileges the artistic pleasure and sociocultural empowerment of its community participants. Its material and aesthetic forms always emerge directly (if not exclusively) from 'the' community, whose interests it tries to express."

Community theatre combines elements of story-telling, drama, singing, movement, mime, and ritual to communicate some ideas, messages, or knowledge to the audience, who are also typically from the same community as the people who make the performance (Kuppers 2007, 3-14). This type of theatre emerges from the partnership between the director or facilitator, along with the participants or actors, and audiences. The actors, who are community members, take an active part in all stages of the production, thus involving the community in the performance for more than just entertainment. Not only does community theatre often erase the divide between audience and performers, but performances often include rituals or ritualized activities that are important for the community. Because of the necessary presence of an audience, theater tied to communities is a reflexive activity, and performances tied to ritual become occasions to create stronger community bonds.

There are many close links between ritual to both theater and communities. Richard Schechner first sees theater as having evolved from ritual performances tied to communities (Schechner 2013, 52-59), but also sees the distinction between ritual and theatre as mainly defined by the context and function of the performance. Importantly, he also views the process of moving from a workshop to rehearsal to public performance sequence as a ritual process in its own right. For community involvement, O'Connor and O'Toole $(2017,63)$ suggest that arts-based and performance practitioners should generate artistic initiatives that create "space for people to reflect on who and how they are in the world and, just as importantly, who they might become." One related source of development here passed through Jerzy Grotowski's theatre work. ${ }^{3}$ He saw his Poor Theatre "as a vehicle... not an escape" that could create

3 I thank one of the reviewers for suggesting that I consider some of these theatre practitioners in this section. 
meaningful "direct, 'live' communion" between performers and audiences, even with in productions with few resources (Grotowski and Barba 2002, 19). His interests in intercultural performance at his Polish Laboratory Theater led him to look beyond European for new influences, and included his own learning with aesthetic and ritual performers from Haiti, India, and Mexico. Eugenio Barba studied with Grotowski, but went on to develop theatre that used cultural exchange (which called "barter") by using theatre tools and techniques with those with no theatrical experience, focusing on how to use the truth of actors' experiences in this work, often to promote social and political change. Also a student of Grotowski, Nicolas Núñez, has also sought to reinvest today's theatre with ritual potentialities and sacred connotations so performances could work as transferable psycho-physical practices for individuals and communities. By developing various "paratheatrical" practices, he sought to produce an "anthropocosmic theatre" whose performance would contribute to both personal and community transformation, as part of a broad cultural "secular sacredness," which seeks to link theatre to old ritual sources. (Núñez 1996) Finally Augusto Boal (1995) suggests that theater works like a telescope, meaning it can focus on details of things that seem remote, obscure or hidden to help make sense of how they are parts of larger patterns or wholes. These features of theater practice, with other community theatre and applied theatre approaches, have helped make performance into a useful set of tools for exploring and showing people's own unique experiences, reflections, interpretations, and stories. (Prentki and Preston 2010; Damrhung 2014)

Inspired by the work of above researchers who link theater to both ritual and community, along with my own experiences in both Muslim and theatre communities, I wanted to develop a creative working process that could bring the two communities together through a performance process that would support my belief that community theatre can create a powerful connection like those found in religious ceremonies. I use the notion of "semi-ritual performance" to name the work done in this project of using them to create new bonds of solidarity and empathy among performers, audiences and communities. The community theatre approach used here could be useful in developing better ways to link Barazan'yee to Muslim communities in urban Bangkok as a kind of semi-ritual performance.

\section{2 What is Barazan'yee?}

This research seeks to use tools from community theatre to better integrate Bara'zanyee into Bangkok Muslim communities. Bara'zanyee is a well-known 
form of Arabic poetry stemming from the famous poetic work, Al-Burdah (The Poem of the Scarf) by the poet Al-Būsinīi (1212-1296). While the poet was ill, he dreamed of the Prophet Muhammad (Peace be upon him ${ }^{4}$ ) and then recovered from his illness. In response to his recovery, he wrote a long poem to express his gratitude towards Allah and to praise the Prophet Muhammad ( $\mathrm{PBUH})$. Chants of parts of the Barazan'yee poem have been included in many practices and it has become associated with a special type of chanting throughout the Muslim world.

The use of Barazan'yee in Muslim practice spread to Southeast Asia as part of an expansion of Muslim communities to the region. It is also linked to the lifestyle of the "Malayu Bakoh" (Malay peoples who migrated to Bangkok at the beginning of Rattanakosin era in the early 19th century) and thus has an important role in the Muslim identity of this community. During every type of Islamic merit activity, called "Kin Boon," parts of the Barazan'yee poem are performed using a special type of chanting. The chant of this poem thus became a key part of Malayu Bakoh practices and identity. Barazan'yee is therefore an important type of performance in Muslim communities in Thailand and other parts of Southeast Asia, one which shapes their identity.

\subsection{Barazan'yee Ceremonies}

"Kin Boon" ceremonies refer to rituals that are related to diverse types of local lifestyle as diverse as house-warming ceremonies and funerals. During these events, a set of verses from the Qu'ran are chanted, seeking to praise Allah. There are also some verses from the Barazan'yee chanted to praise the Prophet Muhammad ( $\mathrm{PBUH})$.

In "Kin Boon" ceremonies, people often gather at the house of the ceremony's host. Before the event starts, participants will sit in a circle around the leader of the ceremony, usually a religious leader or a religious teacher, who is seated in the main space with other participants seated around him. There can be more than one circle if the ceremony has many participants. People will sit in the circle according to their age, gender, or level of religious knowledge. This type of practice is recognized by people in the community informally, but is regularly followed spontaneously. Besides the different types of "Kin Boon" ceremonies, during the birthday of Prophet Muhamad ( $\mathrm{PBUH}$ ) in the third month of the Islamic calendar, Muslims always have a Barazan'yee reading ceremony to celebrate and praise the Prophet.

4 Peace be upon him in the English translation of the phrase Sallā llāhu 'alayhī wa-sallama, which is a phrase Muslims say whenever they refer to the Prophet Muhammad. It is a sign of respect and honor. This paper will use the typical English abbreviation for this phrase, PBUH. 


\section{2}

\section{The Situation of Barazan'yee Today}

For me, since I was growing up, I often questioned the role of Barazan'yee when I participated in it. I saw people who took part in the ceremony, but who did not practice Barazan'yee as a core element of it. For example, when we read Barazan'yee poem in the ceremony, the language used is Arabic, which only a few people in the community could understand. Since they will not understand the meaning of Barazan'yee, the main thing they will get from the ceremony is the sound or the sense of being part of a common group activity, but they are often only waiting to join the banquet after the ceremony is done.

The Barazan'yee ceremony combines local culture with Islamic principles. This results in a tension in the beliefs when people use Barazan'yee for different practices. Some people treat it as a type of incantation. Thus, they join the Barazan'yee ceremony hoping to recover from some illness they may have. This use has led some Muslim groups to forbid this ceremony, since they do not consider it to be "purely" Islamic culture, but rather as a "new" ceremony that is ritualistic, and therefore forbidden. As someone who is part of a Muslim community, I always encounter and observe this tension among people of my community.

Because of these disputes and tensions, community members know the Barazan'yee could be a potential problem, so when we perform it, the leader needs to make an announcement to make clear the objective of Barazan'yee ceremony for participants and observers. Sometimes we use a projector to present the translation of the words so participants can understand the meaning of the Barazan'yee verses. They find a way to live in peace in this situation by holding back harsh criticism and letting other groups use the Barazan'yee as they see fit. However, I would like to invite both sides to take a step back and to recognize Barazan'yee as a form of a poetry with significant historical and artistic value, not as an incantation or something forbidden.

To address this problem by seeking to reconnect Barazan'yee to the people in the community, I realized that they may be able to benefit from my skills in the performing arts. I wanted to use some aspects of the performing arts as tools to allow people who have questions and feel uncomfortable to join Barazan'yee performance. This was the problem which motivated me to do the project when I began. I first wanted to unpack the stories of Prophet Muhammad (PBUH) written in the Barazan'yee through using acting. As Barazan'yee was written in Arabic, most people do not understand it at all. So storytelling and theatre tools will allow performers to blur the line of language barrier and change their sense of perception towards Barazan'yee. I hoped that 
through this new approach would allow people to connect with Barazan'yee regardless of their opinion towards its role in religious ceremonies.

\section{Theatre as Tools to Help Reconnect to Islam}

The above discussion of the situation and problems of Barazan'yee provided a problem space for me to develop a creative approach using tools from community theatre to make a performance using Barazan'yee. ${ }^{5}$ I started this process of developing a concept for making this performance in June 2018 based on a key idea centered on two key points.

First, this performance being devised could allow people to experience the rich meanings of Barazan'yee. As discussed in the previous section, I thought that theatre tools could be used to help reconnect people and to meaningfully interact with the Barazan'yee poem.

Second, this performance project permits participants to convey their stories in relation to Barazan'yee verses. They can share their individual stories with one another and with the community. Even though Barazan'yee relates the great life and powers of the Prophet Muhammad ( $\mathrm{PBUH})$ like the story of a hero, if we want to learn from his life, I think we can follow his simple life and powerful actions. We can engage his life and use it as a guide for our own lives, in part by relating our own life stories to the life story of the Prophet.

Using these two points as a framework for this project, I next started to work with young people who were students at the Islamic center in my community in Bangkok. They were elementary students who I have often worked with before. However, about four months after beginning the project, I modified the working process based on my experience working with Muslim students from the three southern-most provinces in Thailand during a different project. In working with them, I asked them to tell their life stories in relation to the story of life of the Prophet. Since this experience working with students from the south was quite successful, I decided to change the team that I worked with in Bangkok. By turning to a group of eight Anasyid singers from a local religious school called the Masahhatuddeen 2 School and using the new approach I had discovered, these new participants would use their skills in vocal performance. All of them had taken part in the Barazan'yee ceremony several times and some of them had been leaders in their ceremony. Based on their strengths in this area and my experience with southern students, I decided to work with

5 Damrhung (2014) discusses some approaches to doing this that I found useful. 
this team of Barazan'yee singers for the project instead of the young students from my local community.

\section{The Performance Design Process and Its Changes}

After deciding on a group of eight students to work with, I next developed a process of several distinct phases to design a performance with these performers. I wanted them to create their own stories. Farida Jiraphan, a Muslim theatre practitioner in Bangkok, helped me develop the script and facilitate the project. We had previously worked as Muslim actors in Thai contemporary theatre on projects with Muslim youth theatre in local Bangkok communities. Both of us agreed that although developing theatre arts in a religious space or in relation to religion is quite challenging and may face skepticism and criticism, we hoped to use theatre tools to promote peaceful living, following the teachings of Islam. In this research project, Farida also directed the performance, while I work as a dramaturge, modifying the scenes and focusing on the direction of performance script and style of presentation.

Since we were working on a topic tied to religion at an Islamic school with students focusing on religious learning, we needed to carefully deal with the rules of Islam on how men and women could work together. Farida was concerned about wearing the Hijab (head covering) to school while she was involved in the workshop because she does not wear the headscarf in her daily life. Since Masahhatuddeen 2 is an all-male boarding school, however, it was necessary for her to wear it to show her respect. However, there were several incidents that Farida and I faced with questions on the appropriateness of our creative drama process. We were not sure which space would be acceptable to use as our rehearsal space, since it should not be completely closed off from the public as she was the only female in our group. The participants were not sure how to work and communicate with a female facilitator, especially one who was an artist. As a result, they were at first reluctant to talk about their thoughts and feelings. It took some time for the students to tune in and build a trusting relationship with Farida. The situation improved significantly in the second phase of the project after we held a workshop at Burapha University in Bangsaen, and students were able to interact and connect with Farida and me outside of their usual environment much better after that.

In the first phase of the project, Farida and I let students tell their own stories in a process called the "River of Life." Through this process, we asked them to recall events from their lives and to choose incidents that were meaningful to them and to share with others. This process helped them assess their goals 
and choose some stories from their lives that would let them reflect upon what is important to them as well as their personal concerns.

We next helped them re-examine the Prophet's biography. As students of religious studies, they learned about the Prophet Muhammad ( $\mathrm{PBUH}$ )'s as one of the subjects. However, for this project, I asked them to delve into his life with the following questions in mind: "Which story or episode from the Prophet's biography is most relatable to you? Which is most meaningful to you and why?" In asking these questions, I wanted them to journey back in their minds and memories to think about our Prophet in a new light and to ensure that the life of the Prophet - who lived and died centuries ago - remains meaningful and relatable to us now.

All the stories which the eight students selected came from stories that related to their lives. Many of them chose stories that demonstrated the patience of the Prophet. They were impressed by this type of story because of its relevancy and their feeling of empowerment by stories from the Prophet's life.

Doing these activities produced a variety of materials we could use to make the performance. Several of the students who came from backgrounds related to Islamic faith talked about turning points in their lives. Becoming a student at the school was a big transition in their lives. One chose to come to study in the Islamic school as a type of sacrifice for his community. One shared a story about his mistake when he was an early teenager, so that returning to the way of Islam was something for which he had to thank God. These were two examples of core values that I discovered from the students.

Farida and I next discussed with the students about some options on how we could do something with the stories for the performance. One option was to make a performance by developing a story inspired by the stories of the eight students. We also used a second exercise to tell each of their stories directly without combining them to create one cohesive storyline. We tried the first option, but Farida and I noticed that the students felt uncomfortable and were not much interested in "acting" like actors. We noticed this hesitance stemmed from the fact that the performers had little to say over their work, so we felt we needed to move towards a different direction. Having them do something they did not want to do or challenging them too much while de-emphasizing their abilities as singers seemed to be moving in the wrong direction. To become an actor and to take a role as someone is not easy for them. I realized that this working process is a process that does not respect their own unique identities. It was just something that I wanted to do, but it was at odds with what the performers wanted to do. 
In the second phase of the project, running from February to April 2019, Farida and I worked on creating a storyline from students' different stories. Due to problems related to the appropriateness of work between male and female as discussed earlier and the inconsistent workshop sessions, it was difficult to piece all the materials together to create performance, especially in the school's space where students struggled to focus. Thus, I decided to run a three-day workshop at Burapha University where the students would be able to get out of their comfort zone and focus on this project for some time. I later invited Saowanee Vongjinda, who is a facilitator in theatre for development, to meet the students because I wanted to equip them with basic acting skills and to meet a new person to freshen them up after a long working process with Farida and I. Saowanee shared key approaches while working on stage and empowering their performances.

Thus, in the third phase, we returned to what most interested the students and let them develop the project based on their skills and goals. We asked the performers to tell simple, but touching, stories drawn from their own lives. By starting with the basic idea of story-based performance, we tried to link together the two different materials - episodes from the life of the Prophet and personal stories of each individual performer. We combined one of the selected episodes from the Prophet's life with a story from each performer. This became the basic microstructure of the performance. The performers were very interested in this way of doing things, so the process went smoothly.

Connecting to Stories, Connecting to Faith

As a result of the second workshop, Farida, Saowanee, and I had provided the students with a new toolbox to improve their acting and performance - by letting them be true to themselves. Even though they all have beautiful voices for singing, when they performed their own stories in front of a crowd, their chants and movements did not have much meaning in their actions. So Farida and I focused on exercises that aimed to enhance their concentration and movement, and to permit them to focus on better communicating their singing with more meaning. They also learned more about how to stand and move onstage individually and as part of a group, so they would be in a strong position and connect with their friends onstage to better perform as an ensemble.

They then wrote their monologues and tried to perform that monologue perfectly. They needed some training in basic acting techniques. Given what they were performing - their own stories - I advised them to perform with objective and sincerity. We also had to interpret what and why the Prophet 
made certain actions at that time and tried to understand his perspective and the circumstances in each situation.

Among the acting techniques we used were Konstantin Stanislavsky's "magic if,' and Lee Strasberg's "sensory recall" and "emotional recall," all familiar from basic acting courses. By introducing these tools to the performers while retelling the Prophet story's and their own stories, they were able to enhance the power of their storytelling. These basic tools of acting benefited the performers and helped them connect to their stories. Using an acting approach to understand the stories, permitted them to connect with the Islamic faith and to discover their feelings towards the Prophet.

Nonetheless, not every performer felt ready to speak out at first. One boy felt uncomfortable to voice himself out in front of people, even though he is an experienced drummer. So in this project, he was the one who created the drum rhythm, and in his monologue, he used the drum to tell his story and express his truth through the drum sound and his movement of playing it. Although the audience could not hear every word of his monologue, everyone could feel his sincerity by that touching drum sound.

The process of making their own monologues, of learning to write and speak out, and of sharing some of their personal stories helped them to clarify the objective of their life in a public setting. Yet the process required them to tell stories from life in relation to the life of the Prophet. This helped them to better connect themselves to their Islamic faith by using the acting approach.

Connecting to Islamic Faith on a Semi-Ritual Performance Stage

The original Barazan'yee ceremony creates a type of spiritual communication with those who are in the circle of the community. This circuit of communication links the Barazan'yee chanters and those around the chanters. It creates the special experience of a spiritual unity in their mind, even though they may not know the meaning of the words being chanted. I tried to create this sense of spiritual community connected by the voice in the production, too, by not only sensing the voice and the atmosphere of the performance, but also by letting the audience understand the meaning of the stories that were being told. This helped to create a semi-ritual atmosphere and space that could include and communicate something meaningful for both Muslims and non-Muslims

I used the structure of the original Barazan'yee as the main overall macro-structure of the performance, and then use story-theatre techniques to help the performers emphasize the story of the Prophet and their connection 
to it. In this performance, we did not provide the whole story of the Prophet's life, but only some selected stories that were powerful to tell the audience, because they were strongly connected to the lives of the performers, and able to affect both Muslims and non-Muslims.

\subsection{The Structure of the Performance}

The opening of the performance started by the performers singing the song and inviting the audience to sit in circles as would take place in "Kin Boon" activities.

For the second part, the performers went to their own spaces, as the head of the performers greeted the audiences, followed by one performer chanting the opening of Barazan'yee through the end of the first section. He then started the section that is about the birth of the Prophet, when all participants needed to stand to show they welcome and praise the Prophet.

In the third part, all performers went into the audience and give perfume to the audience. Here, the audience would sing along with the performer as occurs in the original Barazan'yee ceremony until the poem finishes, when everybody sits down.

The fourth part has performers start telling five selected episodes from the Prophet's biography, listed below.

1. His solving the problem of peace tied to the Black Stone

2. His praying to Allah to reduce the number of times to pray to five times per day

3. His giving honor at a non-Muslim funeral

4. His feeding the blind man who hates him

5. His final Speech

For the fifth part, the eight performers shared their own stories about something they learned from the Prophet's life, which included the following:

1. Yabirz on his goal of being a student of religious studies

2. Saudi who changed his life for his mother

3. Rashidi who hopes to become a teacher like his father

4. Abdul Latif who learned about owning nothing

5. Fattah who learned something from the death of his mother

6. Figry who hopes to teach the Qur'an like his father

7. Chukri who decided to become a student of religious studies

8. Alawi and his relearning after a car accident ended in the deaths of his friends

In the sixth part, all participants prayed together with the prayer led by the Imam of the community mosque who also joined in the performance, further 
heightening the semi-ritual performance aspect. The performance ends with everyone chanting the "Salawat" or "Praise to the Prophet" together.

Even though the structure used the form of the ceremony that many Muslims are familiar with, giving it a familiar ritual structure, it created a new way of story-telling through actions and movements on stage, thus giving the audience new and enhanced experience through ordinary actions.

In the second public performance, done at the Chang Theatre on April 23, 2019, I modified performance the structure by inserting the "Solaat" or prayer into the performance to better show non-Muslim attendees routine aspects of Muslim life. This performance was done in a Muslim community of Pracha-utit district, Thonburi, so we could hear the Azan or the call of prayer broadcast from the nearby mosque. This helped embed the performance in the regular activities of this Muslim community.

The performance began when the evening prayers just started. After hearing the Azan, the performers lined up and the audience entered the theatre. In the theatre space, one performer did the Azan onstage. When his call ended, all performers and all Muslims in the audience prayed together while non-Muslim audience members observed the prayer ritual in their seats. When the prayers ended, the performance of Barazan'yee started.

The project sought to combine performance and Muslim ritual for diverse communities. I wanted the audience to experience a semi-ritual performance event tied to Islam which would highlight sacred practice through lived performance. In this context, the "ritual" refers to the special religious or spiritual practices or activities of Muslims that connect participants into a unified group while helping to communicate with divine powers. These special ritual activities follow a pattern or structure that has been established long ago. For this research, the performance included some aspects of ritual, such as its aims of communicating with God and of recalling the Prophet's life, but used some of its structure, which resembled the Barazan'yee ceremony in Thai Muslim communities. But both the structure and the setting of the performance were designed to permit one to see it as either a performance or a ritual, depending on one's belief, so it was open to a wider community than just Muslims. For example, at the beginning of the performance as performers invited the audience to pray together, both Muslim and non-Muslim audience could choose to observe or participate at the level they felt comfortable. Given this situation, it is best described as a "semi-ritual performance."

"Semi-ritual performance" thus refers to a performance that uses some elements of ritual to create a "spiritual sensibility" and a "sacred atmosphere" for diverse audiences. It is designed to be open enough so audiences could 
participate in and contribute to its ritual and to its performative dimensions as they saw fit. The performance venue formed a common ground where ritual and performance were both at work on the same level. This dual working structure permitted the diverse audience to experience both ritual and performance simultaneously. Performance is often seen as either a kind of entertainment or as part of a ritual, but this performance aimed to open up a fresh meeting ground where those attending could choose to participate in the performance as they saw fit - as a performance or as a ritual - on the level that suited them. This "paratheatrical" performance resembles some of the work of Nicholas Núñez. (Núñez 1996) As Paveena Chamchoy discussed in her dissertation, ritual is an embodied action where the body is the site for expression and for learning by interacting with a structure and an environment (Chamchoy 2013, 27). Thus, even though audiences were given the choice on how they could participate, their presence already affects the performance process whatever their religious background may be or whether they choose to take action directly in the performance or not.

This new perspective on the performance project also links the audience to spiritual effects, so that those in the audience who do not accept Barazan'yee can still feel comfortable, since this Barazan'yee performance was done on a stage as part of a performance, not in a ritual setting. They could then participate in the Barazan'yee as a form of education or entertainment. For audiences who accept Barazan'yee and who have experienced the Barazan'yee ceremony before, the Barazan'yee performance provides a different way of framing it, so they can have a new experience to Barazan'yee unlike they have had in the past. Thus, the show enabled both party to experience a new viewpoint on the Barazan'yee no matter what one's subject position was. This is because the semi-ritual performance occurred in a common ground for all who were there.

Participants' Journey of the Mind

These performances brought reactions and feedback from the eight performers after participating in this process. This creative research project sought to return the value and the meaning of Barazan'yee to the local urban Muslim community by creating a new performance. I wanted to enhance the meaning and reconnect the heart of Barazan'yee to the community by using tools from theatre performance. The eight students involved in this performance research helped to more firmly ground the piece in the Muslim community. Their feedback focused on five main themes. 
The Prophet's Life: They Do Not Just Remember the Prophet's Life but They also Experience It More Deeply

The eight performers study the Prophet's biography in their school. By having them join this performance as performers, we tried to have them tell about the Prophet's life in relation to their own lives, thus helping the audience to better understand how the life of the Prophet relates to others' lives. By rehearsing many times, the students could immerse themselves into the Prophet's life and discover new connections to their own lives.

\subsection{Sharing and Learning the Lessons from Friends}

By making a performance where everyone shared stories of their own life that were related to the life of the Prophet, the performers could listen to their friends' lives and learn from them, too. Even though they knew each other for many years, they did not know about their lives before they joined the religious school. By sharing these stories with one another, they were able to better understand the life challenges their friends faced. They learned more about the bravery and courage amid challenges each had and about how someone could pass the test of God through the strength of their faith. This is something that the audience could feel and learn from the students, too.

\subsection{Learning and Continuing to Develop Performance Skills}

Most of the feedback from practice and rehearsals related to the students' understanding of how to sing and perform with meaning. They could adapt these lessons for the future when they would perform Barazan'yee. They could feel the difference when they sang with sincerity, or when they performed with an objective, or when they kept focused while performing on stage, so basic acting tools could help them in their future work. They focused on performing well and by feeling the need to express themselves well, which would help them share more with other students at school.

\subsection{Getting Out of the Comfort Zone and Discovering New Possibilities}

Performing in front of people helped give the students more confidence and pride. In the first phase of our work, they had many doubts and concerns about what this performance is going to be. After the first performance, everyone got feedback that made them proud of their work. This helped them to transform from ordinary students of religious studies who knew they could sing into well-rounded performers who had more tools for acting who could deal with new situations. 
Creating a performance allowed the students to tell the stories of their lives and to relate them to the life of the Prophet. This gratified them. Their own stories told of boys who decided to live by the teachings Islam and to practice it themselves in accord with the principles of Islam. They were proud to share their lives to the public and believed that the stories that they shared would benefit the audience.

Audience Perspectives

\subsection{Muslim Audiences}

The performances took place in small theatres. The first performance was held on March 22, 2019. I invited people from the Baan Maa community in eastern Bangkok to see this performance at the black box theatre of Burapha University in Bangsaen, Chonburi Province. This was a new experience for the performers, one which provided them with a new way of participating in the Barazan'yee ceremony on a stage at the theatre. Barazan'yee appeared in a new light for both Muslims and non-Muslims.

The theatre setting, with its new atmosphere, lighting, and space had made a strong impact on the audience. The elements of the performance production led them to interact with Barazan'yee differently.

Most audience feedback stated that the stories told in the performance were those that they knew before, but that this performance gave them a stronger feeling about those stories. The poetry that was chanted helped to move the audience. Even the stories told in the performance were very short compared to the stories in the Barazan'yee poem itself. The five stories of the prophet selected were told in the order from his birth to his death and were very touching. When asked how they felt about seeing the Barazan'yee in performing arts style, many audience members said they were impressed and thought that telling this story through theatre was a good medium to pass on the knowledge of Islam to other communities.

\subsection{Non-Muslim Audiences}

Although this community-based performance was created for the Muslim community, non-Muslims also joined the performance, especially at the second presentation at the Chang Theatre in Thonburi on April 23, 2019, which was open to the public and most of the audience there were non-Muslim.

Muslims at this performance were asked to participate in the Barazan'yee ceremony as a semi-ritual performance. Everyone could join in and become part of the performance. Non-Muslim who joined this performance could be 
either an observer visiting the ritual or to join with other Muslims to learn by proximate participation. Choosing the latter let non-Muslims change their role into a quasi-participant who could connect to the performance like Muslims do.

Non-Muslim audiences provided some interesting feedback. Many said that even though they did not know the meaning of the Arabic words used in the performance, by joining in this performance, they were able to feel peace through the beautiful singing of the performers and to feel the unity of everyone attending. The performance allowed them to discover more of the stories of the Prophet Muhammad (P BUH) than they have ever heard before.

The audience was particularly impressed by the performance done by the eight students who told their own stories. Their stories were simple, yet touching, because they provided many in the audience with direct exposure with Muslims lives, specifically with the lives of religious studies students. This was the first time they listened to Muslim people telling their stories.

Moreover, the semi-ritual performance format allowed non-Muslim audiences to feel and understand the Islamic faith and what all Muslims connect to. The performance showed the life of Muslim people and deconstructed images and stereotypes of Muslims as found in mass media sources, often as threatening, dishonest or bad people in society. Seeing this performance helps non-Muslims to directly connect to the real Muslims who live honestly, devotedly, and gently with their beautiful faith.

\section{My Journey: What I Learned by Doing This Project}

The Barazan'yee project produced three key findings which will be useful for work with Muslim communities and for doing community theatre in the future.

First, I learned more about how to do community theatre. Even though we work as theatre practitioners, directors, actors, and facilitators, working with a community using theatre tools requires special skills in remaining open to learning with and being able to share with artists in the community so that the production develops in ways that will benefit the community where it takes place. Treating the community as only a site and the community members only as actors disrespects both the performers and the community, and turns production into something that is no longer community-based theatre.

I also discovered that the knowledge and practices of modern theatre cannot always be directly applied in community performances, since they may not fit well with community norms and expectations. This is because 
communities often have their own distinct styles of performance. This was true for the Muslim communities I worked with in this project, but it is true for other communities too. Facilitators or directors of community theatre projects would benefit from beginning with the performance styles of the community in question. The director should not try to force new or different style of theatre production that he or she has learned from outside of the community. If that is done, the community's cultural forms and styles may be ignored or even suppressed, and the outcome will not be as good as it could be.

Thirdly, since I was not previously familiar with the diverse, but beautiful, lives of Muslim teenagers, I discovered that my image of a religious studies school as one for poor people and for non-formal education was wrong. Those attending this type of school do so because they value what they learn there. They do not receive any official certificate to acknowledge their attendance. After working with students in this project, I learned more about these students and their goals. They sacrificed part of their lives to pursue religious goals, which I came to admire very much. They practice use the arts they learn to suit their lives and to share their art with the community for its religious value. This helps make their ordinary lives to become extraordinary and impressive.

The Barazan'yee project was done to honor the participants and their knowledge so that they could better see how reciting religious verses for Muslim audiences was an important part of their community life. But it also helped them to see how they could connect to non-Muslims. As a dramaturge and facilitator for this project, I learned that it is most useful to start by finding meaningful stories from community participants. Each community has its own distinctive performance style, which the director should not ignore. By performing twice in theatres in a semi-ritualized environment of the Muslim community, we were able to directly engage the audience and invite them to take part in the performance, whether or not they were Muslims. This helped me to realize that this performance could allow both Muslims and non-Muslims to experience something of Muslim life and to better understand Islamic culture.

Although my initial goal was to restore the value and the meaning of Barazan'yee to the local urban Muslim community by using tools from community-based theatre, the results went beyond this goal. Feedback from audiences and participants not only helped to reconnect Muslims to Barazan'yee in new and unexpected ways through the semi-ritual performance process. It also showed how the performers connected to the Prophet, how Muslim audiences understood the Prophet, and how non-Muslims could better appreciate Islam. 


\section{Supplementary Material}

Supplementary material is available online at https://www.doi.org/10.6084/ mg.figshare.14465169

\section{References}

Beeman, W.O. 1993. "The Anthropology of Theater and Spectacle." Annual Review of Anthropology 22: 369-93.

Boal, Augusto. 1995. The Rainbow of Desire: The Boal Method of Theatre and Therapy. London: Routledge.

Chamchoy, Paveena. 2013. "The Efficacies of Trance-possession Ritual Performances in Contemporary Thai Theravada Buddhism." PhD diss., University of Exeter.

Damrhung, Pornrat. 2014. Applied Theatre: The Use of Drama - Theatre for Development. Bangkok: Chulalongkorn University Press. (In Thai).

D'Onofrio, Alexandra. 2018. "Theater, Anthropology and," The International Encyclopedia of Anthropology. Edited by Hilary Callan. New York: John Wiley \& Sons.

Grotowski, Jerzy, and Euginio Barba, eds. 2002. Towards a Poor Theatre. New York: Routledge.

Kuppers, Petra. 2007. Community Performance: An Introduction. New York: Routledge.

Núñez, Nicolas. 1996. Anthropocosmic Theatre: Rite in the Dynamics of Theatre, Amsterdam: Harwood.

O'Connor, Peter, and John O'Toole. 2017. Editorial. Applied Theatre Research 5(2): 63-5. Prentki,Tim, and Sheila Preston. 2010. The Applied Theatre Reader. New York: Routledge. Schechner, Richard. 2013. Performance Studies: An Introduction, 3rd Edition. New York: Routledge

Van Erven, Eugène. 2001. Community Theatre: Global Perspectives. New York: Routledge. 